\title{
Benzylthiouracil-induced ANCA-associated Vasculitis: A Case Report and Literature Review
}

\author{
Fatima Bensiradi ${ }^{1}$, Mathilde Hignard ${ }^{2}$, Rand Nakkash ${ }^{1}$, Alice Proux ${ }^{1}$, Nathalie Massy ${ }^{3}$, Nadir Kadri ${ }^{1}$, Jean Doucet ${ }^{1}$, Isabelle Landrin ${ }^{1}$ \\ ${ }^{1}$ Fédération de Médecine Gériatrie Thérapeutique, Rouen, France \\ ${ }^{2}$ Département de Pharmacie, $\mathrm{CHU}$ de Rouen, Rouen, France \\ ${ }^{3}$ Centre Régional de Pharmacovigilance, Rouen, France
}

Received: 20/09/2019

Accepted: 23/09/2019

Published: 10/12/2019

\begin{abstract}
How to cite this article: Bensiradj F, Hignard M, Nakkash R, Proux A, Massy N, Kadri N, Doucet J, Landrin I. Benzylthiouracil-induced ANCA-associated
\end{abstract} vasculitis: a case report and literature review. EJCRIM 2019;6: doi:10.12890/2019_001283.

Conflicts of Interests: The Authors declare that there are no competing interest

This article is licensed under a Commons Attribution Non-Commercial 4.0 License

\section{ABSTRACT}

latrogenic antineutrophil cytoplasm antibody (ANCA)-associated vasculitis (AAV) is not exceptional. Many cases of small vessel vasculitis induced by anti-thyroid drugs (ATD), mainly propylthiouracil (PTU), have been reported. We present a case of AAV related to another ATD: benzylthiouracil (BTU) and review the literature. An 84-year-old man with a 4-year history of multinodular goitre with hyperthyroidism was treated with BTU. He presented an acute syndrome with weakness, fever, epigastric pain and abdominal distension. Lactate and lipase tests were normal. An abdominal scan showed a thrombosis of the splenic artery with splenic infarction. We excluded a hypothesis of associated embolic aetiology: atrial fibrillation, atrial myxoma, intraventricular thrombus or artery aneurysm. Exploration of a possible prothrombotic state (complete blood count, haemostasis tests, activated protein $\mathrm{C}$ resistance, factor $\mathrm{V}$ Leiden, protein $\mathrm{C}, \mathrm{S}$, antithrombin III) gave normal results. Tests for antinuclear antibodies (ANA) and antiphospholipid antibodies (APL) were negative. However, testing for p-ANCA, with antimyeloperoxidase (MPO) specificity, was positive: 120.6 CU ( $\mathrm{N}<20.0)$. We did not find other systemic manifestations, except a non-specific kidney failure. BTU was discontinued without steroids or immune-modulating drugs. Subsequently, symptoms disappeared progressively and titres of ANCA fell until normalization, 4 months later. Many patients treated with BTU present a high prevalence of ANCA, mainly, but not exclusively, directed against MPO. Vasculitis, however, remains an uncommon complication. The mechanism of this anomaly remains to be elucidated. Some studies suggest the possibility of an autoimmune reaction initiated by drug bioactivation mediated by neutrophilderived MPO. The present observation is particular because the involved drug was BTU and clinical expression was unusual.

\section{LEARNING POINTS}

- ANCA-associated vasculitis related to anti-thyroid drugs is not exceptional, particularly in patients receiving long-term therapy with thioamides.

- Clinical manifestations are highly variable.

- Treatment consists firstly of stopping the anti-thyroid drug. Introduction of steroids and/or immunosuppressive therapy depends on the severity of organic impairments. Prognosis is less severe than primary ANCA vasculitis.

\section{KEYWORDS}

Anti-thyroid drugs, benzylthiouracil, ANCA vasculitis, hyperthyroidism 


\section{INTRODUCTION}

Antineutrophil cytoplasm antibody (ANCA)-associated vasculitis (AAV) is a group of small vessel systemic vasculitides. ANCAs were first discovered in 1982 by Davies et al. in patients' sera with pauci-immune segmental necrotizing glomerulonephritis ${ }^{[1]}$. ANCAs are autoantibodies targeted against antigens present in the cytoplasm of neutrophils and monocytes. The most common target antigens are proteinase 3 (PR3) and myeloperoxidase (MPO) ${ }^{[2]}$. Anti-thyroid drugs (ATD) are widely used in the treatment of thyroid disorders. Adverse effects related to the use of this medication include agranulocytosis, cutaneous rash, toxic hepatitis and induced lupus-like syndrome. AAV is not an exceptional complication. It has mainly been reported with propylthiouracil (PTU) ${ }^{[3]}$. We present here a case of ANCA-anti-MPOassociated vasculitis related to another thioamide: benzylthiouracil (BTU).

\section{CASE DESCRIPTION}

An 84-year-old male with a clinical history of multinodular goitre and hyperthyroidism presented an acute syndrome with fever and epigastric pain. Past history included hypertension, chronic obstructive airways disease and benign prostatic hyperplasia. Thyrotoxicosis was diagnosed 4 years previously. FT4 was $23.2 \mathrm{pmol} / \mathrm{I}(12-22 \mathrm{pmol} / \mathrm{l})$, TSH was $<0.005 \mathrm{mUI} / \mathrm{I}(0.27-4.2 \mathrm{mUI} / \mathrm{l})$ and TSH receptor antibodies were negative. The patient had been treated and well controlled on BTU $100 \mathrm{mg} /$ day. On admission, blood pressure was 160/82 and his pulse was regular (88/min). The patient was complaining of an epigastric pain with important abdominal distension and a rebound tenderness at the left upper quadrant. A small multinodular goitre was palpable. The obtained laboratory data are shown in Table 1. An abdominal scan showed a distal thrombosis of the splenic artery with splenic infarction. There was no artery aneurysm. An ECG showed a left bundle branch block with lateral repolarization abnormalities. There were no occasional cardiac arrhythmias or atrial fibrillation on Holter monitoring. Echocardiography did not find a thrombus in the left ventricular cavity, no arguments for an endocarditis, but did show an anteroseptal akinesis. The laboratory exploration of a possible prothrombotic state: complete blood account, haemostasis tests, activated protein $C$ resistance, factor V Leiden, protein C, S, antithrombin III, showed normal results. A HIV serology test was negative. We detected a moderate hyperhomocysteinaemia of 21.8 (N:5-15 $\mu \mathrm{mol} / \mathrm{I})$. Testing for antinuclear antibodies (ANA), antiphospholipid antibodies (APL) and ANCA anti-PR3 was negative. However, testing for p-ANCA, with anti-MPO specificity, was clearly positive: $120.6 \mathrm{CU}(\mathrm{N}<20.0)$. We did not find other systemic manifestations, except a kidney failure stage $3 \mathrm{~A}$, without haematuria or proteinuria. BTU was discontinued without steroids or immune-modulating drugs. Subsequently, clinical symptoms progressively ceased. Two months later, thiamazole $10 \mathrm{mg}$ was introduced because of a relapse of the thyroid disorder.

Four months after the cessation of BTU, titres of ANCA-MPO fell until normalized. Serum concentrations of TSH and FT4 were appropriate, and creatinine was stabilized at $140 \mu \mathrm{mol} / \mathrm{l}$.

\begin{tabular}{|c|c|c|c|c|}
\hline Variable & Reference range & $\begin{array}{l}\text { 1st hospital } \\
\text { admission }\end{array}$ & $\begin{array}{c}8 \text { weeks after } \\
\text { cessation of BTU }\end{array}$ & $\begin{array}{l}4 \text { months after } \\
\text { cessation of BTU }\end{array}$ \\
\hline Haemoglobin & $13.5-17.5 \mathrm{~g} / \mathrm{dl}$ & 14.6 & \multirow{13}{*}{$\begin{array}{l}\text { Introduction of } \\
\text { thiamazole }\end{array}$} & 13.1 \\
\hline WBC & $4-10 G / I$ & 7.3 & & 5.7 \\
\hline Platelets & $150-400 \mathrm{G} / \mathrm{I}$ & 313 & & 275 \\
\hline$C R P$ & $<5 \mathrm{mg} / \mathrm{l}$ & 100 & & $<5$ \\
\hline Creatinine & $59-104 \mu \mathrm{mol} / \mathrm{l}$ & 113 & & 140 \\
\hline Urea & $2.5-7 \mathrm{mmol} / \mathrm{l}$ & 6.2 & & 12.2 \\
\hline Proteinuria & $<0.05 \mathrm{~g} / \mathrm{l}$ & $<0.05$ & & $<0.05$ \\
\hline TSH & $0.27-4.2 \mathrm{mUI} / \mathrm{I}$ & 0.32 & & 1.36 \\
\hline FT4 & $12-22 \mathrm{pmol} / \mathrm{l}$ & & & 14.6 \\
\hline NT-proBNP & $<300 \mathrm{ng} / \mathrm{l}$ & 3,529 & & 2,836 \\
\hline Lactate & $0.5-2.2 \mathrm{mmol} / \mathrm{l}$ & 1.05 & & \\
\hline Lipase & $13-60 \mathrm{UI} / \mathrm{I}$ & 25 & & \\
\hline ANCA anti-MPO & $N<20.0 C U$ & 120 & & Negative \\
\hline
\end{tabular}

Table 1. Laboratory data obtained at initial assessment and at follow-up 


\section{SUMMARY OF CASES}

The first induced AAV case was reported in 1992 by Stankus and Johnson, and was related to PTU ${ }^{[4]}$. In 2002, Tieulie et al. described the first case caused by BTU ${ }^{[5]}$. Since then, 17 other observations of induced AAV related to BTU have been reported (see Table 2).

$89 \%$ of cases were female,probably reflecting the female preponderance of thyrotoxicosis. The average age of affected patients was 38.8 years (range 8 to 84 years). All of patients presented Graves' disease,while the average duration of exposure to BTU was 32 months (range 6 to 120 months).

Renal involvemeklet was the most common manifestation (83\%), followed by general symptoms (fever, weight loss, anorexia, asthenia) in $56 \%$ of patients, skin manifestations in $39 \%$, joint pain in $33 \%$, pulmonary vasculitis with alveolar haemorrhage in $22 \%$, with neurological/ neuropsychiatric manifestations having been reported in two cases (11\%). Renal biopsy showed necrotizing glomerulonephritis in 8 cases (44\%) or crescentic glomerulonephritis in 6 (33\%). In cases of skin involvement, biopsy revealed a non-specific leucocytoclastic cutaneous vasculitis. Immunofluorescence was always pauci-immune.

A p-ANCA pattern was present in $78 \%$, whilec-ANCA was seen in only one case (\#16). Undifferentiated positive ANCAs were reported in 3 observations (17\%). In 89\%, ANCAs were directed against MPO. PR3-ANCAs were negative in all sera, when tests were performed.Therapy consisted ofstopping BTU. Additional treatment with steroids and/or cyclophosphamide was initiated in patients presenting severe organic impairment (89\%). In 72\%, therapy resulted in improvement. Concurrently,titresof ANCAs decreased or disappeared progressively but persisted in some cases (\#4,\#10,\#13). In 11\%, renal function declined (\#2, \#15). Death occurred in one case related to Klebsiella pneumoniae septicaemia (\#16).

\section{DISCUSSION}

Our 84-year-old patient had been treated with BTU for 4 years. He did not present severe organic impairment but had sudden pain and fever, with detection of splenic artery thrombosis within a positive ANCA-MPO context. Exclusion of other aetiologies and resolution of symptoms after discontinuing BTU suggested a close relationship between the ATD and clinical manifestations. Exposure duration to BTU in our case was long. According to Gunton et al., there is a significant association between duration of therapy, mainly with PTU, and ANCA positivity $(\mathrm{p}<0.0001)$. Testing patients receiving long-term anti-thyroid medication seems to be interesting ${ }^{[16]}$. A $p$-ANCA pattern with antiMPO specificity seems to be the most common in BTU-induced AAV. To our knowledge, a single abdominal vascular involvement has never been observed previously. Manifestations of AAV related to ATD are variable; they may consist of non-specific constitutional symptoms ${ }^{[17]}$ or may involve vessels in the skin, kidneys, respiratory tract or peripheral nerves ${ }^{[18]}$. The prevalence of ANCA in patients treated with ATD varies from 4 to $46 \%$ while the prevalence of AAV is lower: $0-1.4 \%$. Slot et al. demonstrated that ANCA positivity was significantly related to the use of ATD ${ }^{[19]}$. The presence of ANCAs without vasculitis manifestations suggests that ANCAs alone are not enough to induce vasculitis. Furthermore, high ANCA titres may persist without activation of vasculitis. The pathogenic role of ANCA-MPO in vasculitis seems to be related to sub-classes of anti-MPO antibodies ${ }^{[20]}$.The mechanism by which the ATD, and particularly, thiouracils, may induce AAV remains to be elucidated ${ }^{[8]}$. Jiang et al. showed that PTU, among other medications, was highly cytotoxic in the presence of activated neutrophils ${ }^{[21]}$. Treatment depends on vasculitis localization and clinical severity. Minor symptoms respond well to cessation of the ATD. In cases of seriousrenal damage, treatment with steroids with or without cyclophosphamide should be considered. In cases of life-threatening pulmonary haemorrhage, in addition to steroids and immunosuppressive drugs, plasmapheresis is warranted ${ }^{[18]}$. Derivatives of imidazole are preferred, in cases of relapse, before considering a radical treatment involving surgery or radioactive iodine therapy. Prognosis is less severe than primary ANCA vasculitis, and death due to anti-thyroid therapy-induced AAV is exceptional, related generally to severe alveolar haemorrhage ${ }^{[22]}$. 


\begin{tabular}{|c|c|c|c|c|c|}
\hline Case & Sex/age & Reference & Disease & BTU treatment duration & Symptoms \\
\hline 1 & $M / 70$ & Tieulie et al. [5] & Graves' & 36 months & Renal failure, psychiatric manifestations, anaemia \\
\hline 2 & $F / 28$ & Kaaroud et al. [6] & Graves' & 24 months & Arthralgia, dyspnoea, renal failure \\
\hline 3 & $F / 22$ & Jarraya et al. [7] & Graves' & 12 months & General symptoms, renal failure \\
\hline 4 & $F / 36$ & Braham et al. [8] & Graves' & 36 months & General symptoms, anaemia, renal failure \\
\hline 5 & $F / 8$ & Thabet et al. [9] & Graves' & 16 months & Dyspnoea, pulmonary haemorrhage \\
\hline 6 & $F / 12$ & Hachicha et al. [10] & Graves' & 18 months & Purpura, renal failure \\
\hline 7 & $F / 21$ & Frigui et al. [11] & Graves' & 24 months & Fever, arthralgia, purpura, pulmonary haemorrhage, proteinuria \\
\hline 8 & $F / 37$ & Frigui et al. [11] & Graves' & 84 months & Purpura, renal failure, axonal neuropathy \\
\hline 9 & $\mathrm{~F} / 40$ & Frigui et al. [11] & Graves' & 22 months & Fever, arthralgia, leg ulcers \\
\hline 10 & $M / 50$ & Trimeche Ajmi et al. [3] & Graves' & 8 months & General symptoms, renal failure \\
\hline 11 & $F / 28$ & Chebbi et al. [12] & Graves' & 15 months & Necrotic purpura, fever \\
\hline 12 & $F / 48$ & Houissa et al. [13] & Graves' & 12 months & Leg ulcers, arthralgia, renal failure, anaemia \\
\hline 13 & $F / 36$ & Kaaroud et al. [14] & Graves' & 36 months & General symptoms, renal failure, alveolar haemorrhage \\
\hline 14 & $F / 61$ & Kaaroud et al. [14] & Graves' & 6 months & Arthralgia, renal failure \\
\hline 15 & $F / 36$ & Kaaroud et al. [14] & Graves' & 49 months & General symptoms, fever, anaemia, renal failure \\
\hline 16 & $F / 33$ & Kaaroud et al. [14] & Graves' & 120 months & General symptoms, fever, alveolar haemorrhage, renal failure \\
\hline 17 & $F / 19$ & Kaaroud et al. [14] & Graves' & 36 months & Fever, renal failure \\
\hline 18 & F/68 & Delattre et al. [15] & Graves' & $>12$ months & Purpura, arthralgia, renal failure \\
\hline
\end{tabular}

\begin{tabular}{|c|c|c|c|c|c|c|}
\hline Case & Pathology & ANCA & MPO & Management & Outcome & ANCA control \\
\hline 1 & Pauci-immune necrotizing GN & $P$ & + & Ster, ceased BTU, carbimazole/RI therapy & Improved & Decreased \\
\hline 2 & Crescentic GN & $P$ & + & Haemodialysis, Ster, CYC, ceased BTU & Chronic renal failure & Persistence \\
\hline 3 & Crescentic GN & $?$ & + & No treatment, BTU continued & Stable & $?$ \\
\hline 4 & Pauci-immune necrotizing GN & $P$ & + & Ster, CYC, ceased BTU & Improved & Persistence \\
\hline 5 & None available & $P$ & + (anti LF, Elast) & Ster, ceased BTU & Improved & Negative \\
\hline 6 & $\begin{array}{l}\text { Cutaneous vasculitis, } \\
\text { pauci-immune necrotizing GN }\end{array}$ & $?$ & + & Ster, ceased BTU & Improved & Negative \\
\hline 7 & Necrotizing GN & $P$ & + & Ster, ceased BTU, RI therapy & Improved & Negative \\
\hline 8 & $\begin{array}{l}\text { Leucocytoclastic cutaneous } \\
\text { vasculitis }\end{array}$ & $P$ & + & Ster, ceased BTU, RI therapy & Improved & Negative \\
\hline 9 & $\begin{array}{l}\text { Leucocytoclastic cutaneous } \\
\text { vasculitis }\end{array}$ & $P$ & + & Ster, ceased BTU, RI therapy & Improved & $?$ \\
\hline 10 & Pauci-immune necrotizing GN & $P$ & + & Ster, CYC, ceased BTU & Improved & Persistence \\
\hline 11 & $\begin{array}{l}\text { Leucocytoclastic cutaneous } \\
\text { vasculitis }\end{array}$ & $P$ & + & Ceased BTU, carbimazole/RI therapy & Improved & Negative \\
\hline 12 & Pauci-immune necrotizing GN, & $P$ & + & Ster, CYC, ceased BTU & Improved & Decreased \\
\hline 13 & $\begin{array}{l}\text { Leucocytoclastic cutaneous } \\
\text { vasculitis }\end{array}$ & $P$ & + & Ster, CYC, plasma exchange, ceased BTU & Improved & Persistence \\
\hline 14 & Crescentic GN & $P$ & + & Ster, CYC, ceased BTU & Stable & $?$ \\
\hline 15 & Crescentic GN & $P$ & + & Ster, ceased BTU, haemodialysis & Chronic renal failure & $?$ \\
\hline 16 & Crescentic GN & c & - & $\begin{array}{l}\text { Ster, CYC, ceased BTU, } \\
\text { haemodialysis/plasma exchange }\end{array}$ & Death (septicaemia) & $?$ \\
\hline 17 & Crescentic GN & + & $?$ & Ster, ceased BTU & Improved & $?$ \\
\hline 18 & Necrotizing GN & $P$ & + & Ster, CYC, ceased BTU, thyroidectomy & Improved & Negative \\
\hline
\end{tabular}

Table 2. Cases of BTU-induced ANCA-associated vasculitis: a review of the literature

BTU: benzylthiouracil; Ster: steroid; CYC: cyclophosphamide; RI: radioactive iodine therapy; GN: glomerulonephritis 


\section{REFERENCES}

1. Davies DJ, et al. Segmental necrotising glomerulonephritis with antineutrophil antibody: possible arbovirus aetiology? Br Med J (Clin Res Ed) 1982;285:606.

2. Rowaiye OO, et al. The kidneys and ANCA-associated vasculitis: from pathogenesis to diagnosis. Clin Kidney J 2015;8(3):343-350.

3. Trimeche Ajmi S, et al. Benzylthiouracil-induced glomerulonephritis. Case Rep Med 2009;2009:687285.

4. Stankus SJ, Johnson NT. Propylthiouracil-induced hypersensitivity vasculitis presenting as respiratory failure. Chest 1992;102:1595-1596.

5. Tieulie N, et al. Glomerulonephrite associee aux ANCA secondaire au benzylthiouracile. Rev Med Interne 2002;23:853-856.

6. Kaaroud H, et al. Une vascularite associant une atteinte renale et pulmonaire au cours d'une maladie de Basedow traitee par le BTU. Rev Med Interne 2002;23:857-861.

7. Jarraya F, et al. MPO-ANCA-positive crescentic glomerulonephritis associated with benzylthiouracil therapy: report of the first case. Nephrol Dial Transplant 2003;18:2421-2423.

8. Braham A, et al. Vascularite à ANCA induite par le benzylthio-uracile. Presse Med 2004;33:1331-1333.

9. Thabet F, et al. ANCA-associated diffuse alveolar hemorrhage due to benzylthiouracil. Eur J Pediatr 2006;165:435-436.

10. Hachicha M, et al. Vascularite avec atteinte rénale et ANCA après prise de benzylthio-uracile chez l'enfant. Nephrol Ther 2007;3:147-151.

11. Frigui M, et al. Vascularite à ANCA induite par le benzylthio-uracile: étude de trois observations et revue de la littérature. Ann Endocrinol $2008 ; 69: 517-522$.

12. Chebbi W, et al. Vascularite cutanée à ANCA induite par le benzylthio-uracile: à propos d'un cas et revue de la littérature. Rev Med Interne 2013;34:561-564.

13. Houissa F, et al. Vascularite systémique à ANCA induite par le benzylthiouracile. Tunis Med 2014;92:428-430.

14. Kaaroud H, et al. Glomérulonéphrite associée aux anca induite par le Benzylthiouracile chez des patients ayant une maladie de Basedow. Tunis Med 2015;93:696-701.

15. Delattre E, et al. Vascularite à ANCA associée aux anti-thyroïdiens de synthèse, à propos d'un cas lié au benzylthiouracile. Rev Med Interne 2017;38 (Suppl 1):A160-A161.

16. Gunton JE, et al. Prevalence of positive ANCA in patients receiving anti-thyroid medication. Eur J Endocrinol 2000;142:587-590.

17. Dolman KM, et al. Vasculitis and antineutrophil cytoplasmic autoantibodies associated with propylthiouracil therapy. Lancet 1993;342:651-652.

18. Gunton JE, et al. Anti-thyroid drugs and ANCA positive vasculitis. A case report and review of the literature. J Clin Endocrinol Metab 1999;84:13-16.

19. Slot MC, et al. Occurrence of ANCA and associated vasculitis in patients with hyperthyroidism treated with anti-thyroid drugs: a long-term follow-up study. Arthritis Rheum 2005;53:108-113.

20. Locke IC, et al. A comparison of the characteristics of circulating anti-myeloperoxidase autoantibodies in vasculitis with those in non-vasculitic conditions. Clin Exp Immunol 1999;115:369-376.

21. Jiang X, et al. Transformation of lupus-inducing drugs to cytotoxic products by activated neutrophils. Science 1994;266:810-813.

22. Batchelor N, Holley A. A fatal case of propylthiouracil-induced ANCA-positive vasculitis. MedGenMed 2006;8(4):10. 